\title{
UMA ANÁLISE SOBRE O REFERENCIAL CURRICULAR DE LÍNGUA ESTRANGEIRA DO ESTADO DO TOCANTINS SOB A PERSPECTIVA DA CRIATIVIDADE E DA INTERDISCIPLINARIDADE
}

\author{
Jônatas Gomes Duarte * \\ Maria José do Pinho **
}

\begin{abstract}
Resumo: O presente artigo tem como objetivo principal analisar o Referencial Curricular de Língua Estrangeira (Inglês) do Ensino Fundamental do Estado do Tocantins (RCLE/TO). Este estudo se define como uma pesquisa documental, de abordagem qualitativa e de caráter bibliográfico. Buscou-se verificar se a interdisciplinaridade e a criatividade são conceitos trabalhados na composição desse documento para auxiliar os professores e alunos no processo de ensino-aprendizagem. Constatou-se que a palavra criatividade é contemplada no RCLE/TO e que o documento analisado indica a necessidade de uma linguagem dialógica. O RCLE/TO traz orientações a serem seguidas, espécie de subsídio para a organização mental que permitirá ao professor efetivar os conteúdos a serem trabalhados no espaço escolar.
\end{abstract}

Palavras-chave: Criatividade. Interdisciplinaridade. Ensino-aprendizagem.

\begin{abstract}
This paper aims to analyze the Curriculum Reference of Foreign Language (English) of Elementary Education in the State of Tocantins (CRFL / TO). This study defines as desk research, a qualitative and bibliographical approach. The interdisciplinarity and creativity were checked whether they are concepts used in the composition of this document to help teachers and students in the teaching-learning process. It was found that the word creativity is addressed in CRFL / TO and the document analysis indicates the need for a dialogic language. The CRFL / TO brings guidelines to follow, sort of allowance for mental organization that will allow the teacher to carry the contents to be worked within the school.
\end{abstract}

Keywords: Creativity. Interdisciplinarity.Teaching-learning.

\section{Introdução}

O presente texto teve como objetivo principal analisar o Referencial Curricular de Língua Estrangeira (Inglês) do Ensino Fundamental do Estado do Tocantins (RCLE/TO 2008). Buscou-se verificar se a interdisciplinaridade e a criatividade são conceitos trabalhados na composição do RCLE/TO e se possibilita aos professores e aos alunos transformar as informações teóricas em conhecimentos práticos no cotidiano escolar.

Atualmente, há duas vertentes que sinalizam para uma contradição: de um lado a extraordinária quantidade de informações em circulação que possibilita o crescimento das expectativas humanas; de outro, o enfraquecimento da escolha, da autonomia e da criatividade humana. É fato que a evolução social permitiu novas possibilidades de liberdade individual, todavia, as agências de ensino, por si mesmas tendenciosas a sistemas meramente estatísticos, quantitativos e uniformizadores, têm tornado incolores a descoberta e o conhecimento.

Os sistemas de ensino oficiais se mostram em demasiado administrativos, políticos e, concomitantemente, rígidos, não muito abertos a transformações inovadoras, embora em suas formulações atestem terem sido construídos sob a colaboração de agentes educacionais e sociais, não sendo de tudo uma inverdade.

\footnotetext{
"Doutorando do Programa de Pós-Graduação em Letras: Ensino de Língua e Literatura da Universidade Federal do Tocantins - UFT. E-mail: jonatas@uft.edu.br

** Doutora em Educação e professora do Programa de Pós-Graduação em Letras: Ensino de Língua e Literatura da Universidade Federal do Tocantins - UFT
} 
Quando analisados, na teoria, admitem percursos de educação livre, eficaz e criativa, mas revelam nas orientações didáticas descontextualização que perpassa desde os norteamentos burocratizados ao professor, aos recursos e equipamentos a serem utilizados para a elucidação do conteúdo que não permeiam a realidade do espaço escolar.

Pretende-se no, decorrer deste texto, responder às seguintes questões: De que maneira a interdisciplinaridade e a criatividade se apresentam no RCLE/TO (2008?). Quais as contribuições ofertadas ao professor que o possibilite a desenvolver a própria criatividade, de modo que o aluno seja também motivado a desenvolver processos cognitivos criativos? Como esses norteadores trabalham a interdisciplinaridade e a criatividade na formulação dos parâmetros para o ensino?

Espera-se com este estudo identificar se na composição desse documento há dialogicidade entre os atores educacionais e os diferentes saberes, especificamente para o ensino da Língua Estrangeira (LE).

\section{Percurso metodológico e identificação da natureza da pesquisa}

Este estudo se define como uma pesquisa documental, de abordagem qualitativa e de caráter bibliográfico. Para o andamento da investigação analisou-se o Referencial Curricular de Língua Estrangeira Moderna - Inglês para o Ensino Fundamental $-6^{\circ}$ ao $9^{\circ}$ ano, do Estado do Tocantins e publicações que veiculam a criatividade e o ensino como objetos de estudo. Buscou-se verificar se a interdisciplinaridade e a criatividade são conceitos trabalhados na composição do RCLE/TO para auxiliar os professores e alunos no processo de ensinoaprendizagem.

Inicialmente, foi realizado um levantamento bibliográfico sobre o tema, visando à identificação do maior número possível de informações sobre a temática em questão (MARCONI; LAKATOS, 2008), com ênfase nos trabalhos já realizados sobre interdisciplinaridade e criatividade.

A pesquisa seguiu os pressupostos teóricos da linguística aplicada ao ensino de língua estrangeira e a proposta pedagógica da escola criativa. Para tanto teve embasamento em teóricos como Almeida Filho (2002) e Saturnino de la Torre (2011 e 2012).

\section{A criatividade e a educação}

O potencial humano para transformar e criar, proposto por Torre (2011), relaciona a criatividade com a adversidade, por entender que é possível enfrentar as adversidades (pessoais, profissionais, sociais, econômicas, globais, entre outros) com criação e inovação. A criatividade e a educação são as melhores estratégias que os seres humanos dispõem para seu desenvolvimento, tanto social quanto intelectual e científico.

A educação e a criatividade caminham lado a lado com o propósito de alcançar as condições e os métodos possíveis para o desenvolvimento da criatividade e a inovação no ensino.

Para Antunes (2009), a criatividade é uma capacidade inerente aos seres humanos para criar, inovar e inventar. Os seres humanos são capazes de ser criativos e inovadores, ou seja, todos os humanos têm esse poder nato de criar e produzir resultados eficientes, mas para ser desenvolvido, requer que seja por meio da educação e da experiência. 
A criatividade e a inovação, na educação, podem acontecer no momento em que surge uma ideia e há uma ação, ou seja, uma atitude que pode germinar, crescer e se desenvolver em uma sala de aula, em uma disciplina, em um curso ou em uma instituição.

Segundo Torre (2012), a definição de inovação educativa é um processo de mudança que está relacionado com a prática do currículo, materiais pedagógicos e, principalmente, com ideias e atitudes. Para a consolidação e o crescimento institucional e pessoal.

A inovação advém da interação entre as condições socioculturais, contextuais e pessoais de quem decide iniciar um projeto de mudança. Pode referir-se tanto aos conteúdos, metodologias, recursos didáticos, avaliação, como ao âmbito organizacional da instituição e na relação e comunicação entre os profissionais, formação dos professores e a melhora do ensino-aprendizagem.

\begin{abstract}
A inovação educativa, tal como entendemos, é um processo dinâmico e aberto, de caráter multidimensional e complexo, inserido em uma realidade sociocultural e humana que busca o crescimento pessoal, institucional e o aprimoramento social, portanto, requer estratégias de participação colaborativa. A inovação não é um sucesso, mas um processo que tem lugar em um grupo humano e procura mudar algum aspecto de suas relações ou funcionamento. (TORRE, 2012, p. 18, tradução nossa).
\end{abstract}

No ambiente escolar, para que o aluno processe as ações solicitadas e obtenha êxito em seu aprendizado, as diretrizes que permeiam a construção do material a ele disponibilizado necessitam incitá-lo ao pensamento lógico, à capacidade de análise crítica e à criatividade. Logo, o material disponibilizado precisa ser inovador, sensível às necessidades do aprendiz, elaborado segundo parâmetros procedimentais selecionados e adequados às necessidades contextuais do aluno. Tal ação exige criatividade por parte do design didático.

Segundo o Referencial Curricular do Tocantins (RC/TO), quando se refere à abordagem de conteúdo é importante que "o professor tenha ousadia para propor "coisas novas", testar sua criatividade e a de seus alunos em situações estimulantes de aprendizagem, deve-se, portanto, levar o aluno a "mergulhar" em experiências significativas de aprendizagens". (TOCANTINS, Referencial Curricular do ensino Fundamental, 2008, p. 303).

A criatividade, na concepção de Barreto (1982 apud COSTA; MARINS, 2013), envolve o pressuposto básico de que uma boa ideia é aquela que soluciona um problema de forma singular. A autora sugere um método que divide o processo criativo em quatro fases:

(1) preparação, envolvendo a coleta e manipulação do maior número possível de dados e elementos pertinentes ao problema que se deseja resolver (refletir sobre esses dados, podendo-se ler, anotar, discutir, consultar, e assim, cultivar a concentração no assunto);

(2) incubação, fase na qual se deve descansar desligar-se do problema, abandonar os detalhes, os números, as formulações, a procura. Nesta fase ela relata que o inconsciente, desimpedido pelo intelecto, começa a elaborar as inesperadas conexões que constituem a essência da criação;

\footnotetext{
${ }^{1}$ La innovación educativa, tal como nosotros la entendemos, es um processo dinâmico, y aberto, de carácter multidimensional y complejo, inserto em una realidad sociocultural y humana que busca el crecimiento personal, institucional y mejora social, por lo que requiere estratégias de participación colaborativa. La innovación no es um sucesso sino um processo que tiene lugar em um grupo humano y busca cambiar algún aspecto de sus relaciones o funcionamento. (TORRE, 2012, p. 18).
} 
(3) iluminação, relacionada ao insight - ideia ou ideias que podem solucionar o problema e que aparecem espontaneamente;

(4) verificação, representa um retorno ao consciente, à racionalidade. A ideia deve submeter-se à previsão das reações de outrem, fazendo-se necessários testes e avaliações. É nesse estágio que entram em cena as exigências de adequação (COSTA e MARINS, 2013, p. $11)$.

O panorama educacional na atualidade tem sido caracterizado por quatro aspectos ou tendências principais (COSTA; MARINS, 2013, p.4):

1) acesso à informação proporcionado pelas TIC (CASTELLS, 1999); 2) excesso de informação (Vaz, 2000); 3) mudança do paradigma educacional centrado no professor e 4) transformações perceptivo-cognitivas por parte do novo tipo de leitor, que se forma a partir do acesso às novas tecnologias da Informação, um "leitor imersivo" e visual. (COSTA; MARINS, 2013, p.4):

Essas tendências foram possibilitadas pela informática, que permitiu questionar o velho paradigma educacional com base na compreensão dos processos cognitivos que ocorrem no aprendiz e na análise dos procedimentos realizados pelo aluno (MORAES, 2003). Para a autora, fundamentam esse ideal as teorias do conhecimento e da aprendizagem trabalhadas por vários teóricos (dentre os quais Piaget, Freire e Gardner), cujas ideias estão fundamentadas na multidimensionalidade da mente humana, numa visão de totalidade do processo de construção do conhecimento com base em aspectos físico, biológico, mental, psicológico, sociocultural inseparáveis, bem como na subjetividade do sujeito e em sua participação na construção do conhecimento.

Essas teorias e conhecimentos envolvem metodologias de ensinar e de aprender diferenciadas. Todavia, em um aspecto, todas as que buscam um formato eficaz e eficiência no aprendizado verticalizam para um objetivo: trabalhar conteúdos de ensino-aprendizagem, utilizando as ferramentas de informação e comunicação disponíveis, com base em um design didático inovador ${ }^{2}$ que promova a interação, a colaboração, o diálogo e a criatividade entre os diferentes saberes em sala de aula.

Essa perspectiva se mostra em consonância com o que determina os Parâmetros Curriculares Nacionais para a Língua Estrangeira (1998). Especificamente, quando esse documento reitera a necessidade do ensino possibilitar ao aluno fazer uso de diferentes fontes de informação e recursos tecnológicos para adquirir e construir conhecimentos.

É nessa linha de raciocínio que buscamos analisar se a criatividade como recurso, tem sido incentivada nos processos educativos que envolvem a composição do Referencial Curricular do Ensino Fundamental do Estado do Tocantins ao ensino de (LE).

\section{A interdisciplinaridade no ensino-aprendizagem de língua estrangeira}

A interdisciplinaridade, nos Parâmetros Curriculares Nacionais (PCN), "refere-se a

\footnotetext{
${ }^{2}$ O horizonte semântico do termo inovação é bastante amplo, ao menos tanto quanto os processos mentais que estão em sua origem e as mudanças que engendra. Mediante combinações sempre novas de ideias e eventos, a inovação causa mudanças e descontinuidade em paradigmas científicos, culturais e sociais. Inovação é, sobretudo, uma capacidade de a mente combinar elementos lúdicos e lógicos, extrair de dados aparentemente banais elementos novos e inusitados, produzir respostas divergentes e criativas, gerar hipóteses, cenários e soluções diferentes de maneira quase casual, até fora de uma lógica estruturada (MALDONATO; DELL'ORCCO, 2010, não paginado).
} 
uma abordagem epistemológica dos objetos de conhecimento" (BRASIL, 1997, p. 30), através do diálogo entre disciplinas ou áreas do saber. Ela "supõe um eixo integrador, que pode ser o objeto de conhecimento, um projeto de investigação, um plano de intervenção" (BRASIL, 2002, p. 88). O RC/TO afirma que:

O desenvolvimento de habilidades e competências na sala de aula implica o conhecimento do contexto histórico social, considerando a importância da interdisciplinaridade, a diversidade cultural presente nas relações educacionais de modo que os conhecimentos sejam reorganizados e modificados, permitindo uma aprendizagem significativa, que favoreça ao indivíduo interagir e transformar a realidade. (TOCANTINS, Referencial Curricular do ensino Fundamental, 2008, p. 20).

A interdisciplinaridade deve ser condição sine qua non para a ação criativa e inovadora que visa à interação e a motivação em sala de aula. Desta forma, acredita-se que podemos contribuir para a formação do sujeito reflexivo, ativo e crítico tornando a aprendizagem mais atraente, prazerosa e significativa. Segundo Lück (2010) a interdisciplinaridade é:

(...) o processo que envolve a integração e o engajamento de educadores, num trabalho conjunto de interação das disciplinas do currículo escolar entre si e com a realidade; de modo a superar a fragmentação do ensino objetivando a formação integral do aluno, a fim de que possam exercer criticamente a cidadania, mediante uma visão global de mundo e serem capazes de enfrentar os problemas complexos, amplos e globais da realidade atual. (LÜCK, 2010, p. 47).

Para Fazenda (2010) a interdisciplinaridade 'só vale a pena' se for considerada um método eficaz para alcançar metas educacionais pré-estabelecidas e compartilhadas por todos os membros da instituição escolar. O contrário disso pode transformá-la em um esforço desnecessário para atingir metas que poderiam ser alcançadas de modo menos trabalhoso.

É importante ressaltar, conforme Fazenda (2005), que o campo da interdisciplinaridade não é único nem estável, visto que se constrói sob diferentes níveis e varia a sua interpretação conforme vai sendo apropriado pelos processos educativos.

De acordo com Fazenda (2001), muitos educadores sentem uma sensação incômoda quando ouvem falar sobre a interdisciplinaridade:

[...] ela (a interdisciplinaridade) é apenas pronunciada e os educadores não sabem bem o que fazer sem ela. Sentem-se perplexos frente à possibilidade de sua implementação na educação. Essa perplexidade é traduzida por alguns na tentativa da construção de novos projetos para o ensino. Entretanto, percebe-se em todos esses projetos a marca da insegurança. (FAZENDA, 2001, p. 15).

Nesse contexto, possivelmente, as dificuldades dos professores na prática da interdisciplinaridade na área do ensino de LE sejam consequência dos diferentes entendimentos do próprio conceito de interdisciplinaridade. Além disso, apresentam-se outros empecilhos que barram efetivamente a interdisciplinaridade na escola, tais como: hierarquização das disciplinas; ausência de planejamentos efetivos em conjunto e a falta de diálogos entre os saberes.

Os Parâmetros Curriculares Nacionais (PCN), afirmam que:

(...) a disciplina Línguas Estrangeiras na escola visa a ensinar um idioma estrangeiro e, ao mesmo tempo, cumprir outros compromissos com os educandos, como, por 
exemplo, contribuir para a formação de indivíduos como parte de suas preocupações educacionais. (BRASIL, 2006, p. 91).

Segundo o (RCLE/TO), o aluno de $6^{\circ}$ ao $9^{\circ}$ ano do ensino fundamental deve desenvolver a seguinte competência: "atuar de forma solidária respeitando a inclusão, as diferenças individuais, as regras pré-estabelecidas durante as atividades em sala de aula". (TOCANTINS, Referencial Curricular do ensino Fundamental, 2008, p. 222). Para o desenvolvimento e aquisição dessa competência o professor deverá:

\begin{abstract}
Desenvolver projetos, workshops, utilizando-se de materiais lúdicos que auxiliem na ampliação dos conhecimentos linguísticos fortalecendo o relacionamento interpessoal do grupo; Trabalhar com os diversos temas transversais ampliando os conhecimentos propiciando aos alunos o entendimento e o respeito às diversidades étnicas, bem como as diferenças e limites individuais e coletivos. (TOCANTINS, Referencial Curricular do ensino Fundamental, 2008, p. 222).
\end{abstract}

As aulas de LE podem ser mais do que simplesmente aulas de regras gramaticais, pois podem ser extremamente eficientes, à medida que abrem espaço para que os alunos possam interagir e expressar seus conhecimentos de mundo e assim construir o conhecimento em conjunto com o professor, de forma comunicativa.

A abordagem comunicativa se caracteriza por ter "o foco no sentido, no significado e na interação propositada entre os sujeitos que estão aprendendo uma nova língua estrangeira" (ALMEIDA FILHO, 2002, p. 41). Sendo assim, o aluno precisa engajar-se em situações e contextos sociais e culturais autênticos na língua-alvo, nos quais ele realmente produza sentidos colaborativos com seus interlocutores. Uma abordagem é uma força que imprime uma determinada ação ao processo de ensinar.

Os PCN para a Língua Estrangeira (1998) ressaltam que:

(...) ao ensinar uma língua estrangeira, é essencial uma compreensão teórica do que é linguagem, tanto do ponto de vista dos conhecimentos necessários para usá-la quanto ao uso que fazem desses conhecimentos para construir significados no mundo social. (BRASIL, 1998, p. 27).

Deste modo, o professor deve ter conhecimento do que significa a linguagem em seu sentido amplo, para favorecer a construção de significados na sala de aula. O aluno deve usar todo o seu conhecimento para conseguir construir significados sócio-internacionistas. Os PCN acentuam que o domínio da (LE) possui relação estreita com a possibilidade de plena participação social:

A aprendizagem de Língua Estrangeira é uma possibilidade de aumentar a percepção do aluno como ser humano e como cidadão. Por isso, ela vai centra-se no engajamento discursivo do aluno, ou seja, em sua capacidade de se engajar ou engajar outros no discurso, de modo a poder agir no mundo social. Para que isso seja possível é fundamental que o ensino de língua Estrangeira seja balizado pela função social desse conhecimento na sociedade brasileira. (BRASIL, 1998, p.63).

A disciplina de LE tem o objetivo de produzir cidadãos capazes de participar ativamente no discurso e contribuir para o engajamento discursivo de outros, numa troca constante de conhecimentos, por meio do caráter sócio-interacional que norteia o ensino e a aprendizagem.

O processo de ensino-aprendizagem de LE deve ir além das habilidades linguísticas. Para tanto, é necessário que os docentes possam contribuir para formar alunos reflexivos, 
transformadores e críticos, ou seja, cidadãos pensantes. Desta forma, os alunos serão inseridos como partícipes ativos na sociedade.

Nesse sentido, recentes pesquisas na área da educação têm se baseado nas ideias de Wertsch (1993, apud COSTA; MARINS, 2013), cujas ideias defendem a mediação como instrumento necessário aos processos educativos (perspectiva da ação mediada). Busca-se com estes estudos identificar no discurso dos alunos como se processa a construção coletiva do conhecimento (BAKHTIN, 2003), partindo da prerrogativa de que a ação humana, e por consequência à educativa, emprega ferramentas culturais e a linguagem como "instrumentos mediadores".

Bakhtin (2003) constrói sua abordagem sobre a linguagem mediante conceitos de enunciado, voz, linguagem social e gêneros discursivos. $\mathrm{O}$ enunciado configura em sua visão a unidade básica da comunicação verbal, segundo ele, o discurso do falante vem pleno dos significantes do ouvinte, a quem pretende atingir, numa compreensão real responsiva e é neste aspecto que esse autor considera que toda compreensão verdadeira é dialógica por natureza. Os discursos se correlacionam com outros discursos e com o contexto social em que se realizam e neste sentido, todos os processos comunicativos humanos, seja verbal ou não, configuram um diálogo de vozes, pois na produção de um enunciado, ao menos duas vozes se fazem presentes: a do falante (locutor) e a do ouvinte (interlocutor).

Wertsch (1993, apud COSTA; MARINS, 2013, p. 8), para quem a ação mediada é perspectivizada, afirma que Bakhtin utiliza outras definições na construção do enunciado, dentre as quais:

a) ventrilocução: processo de elaboração de enunciados a partir do uso de linguagens sociais, discurso próprio de um estrato específico da sociedade. Ex.: jargões profissionais e as linguagens de autoridade de grupos diversos (militares professores, entre outros);

b) interanimação de vozes: as palavras do outro - apesar de não estar presente influência e sinais perceptíveis são constatados na fala do primeiro sujeito;

c) construção híbrida: enunciado feito pela mescla de diferentes vozes;

d) gênero discursivo: tipo de enunciado que reflete características de atividades humanas e de suas comunidades discursivas e/ou de cada campo de conhecimento (ex.: diálogo científico ou de aprendizagem).

Os conceitos apresentados pelo autor são observáveis na composição de diretrizes norteadores e materiais didáticos escolares. Ao se conceber um material ou na criação de uma normatização curricular, ocorre a construção híbrida (as vozes sociais, políticas, ideológicas, do órgão normatizador, entre outros), também enuncia-se uma perspectiva de Inter animação de vozes, como se a voz do outro, daquele que vai fazer uso do material didático/pedagógico disponibilizado (escola, professor, aluno) também ali esteja presente, mesma que, normalmente, apenas uma amostra de resultados isolados tenha sido levantada nesse sentido.

\section{Reflexão sobre o referencial curricular do Tocantins para o ensino de língua estrangeira no ensino fundamental}

$\mathrm{O}$ advento dos PCN não resultou em respostas diretas às demandadas das salas de aula. Em face dessa lacuna e pela exigência legal que impõe aos Estados a formulação de suas próprias diretrizes, a Secretaria de Educação e Cultura do Estado do Tocantins criou o Referencial Curricular para o Ensino Fundamental $-1^{\circ}$ ao $9^{\circ}$ ano (RC/TO); (SILVA; MELO, 2009). 
Assim, o presente Referencial Curricular, que foi baseado nos Parâmetros Curriculares Nacionais, visa um melhor desenvolvimento do processo ensino e aprendizagem dessa área, através da contextualização de conteúdos, flexibilidade curricular, interdisciplinaridade, visão globalizado do ambiente, conservação e uso racional da natureza, diálogo entre senso comum e ciência, valorização do conhecimento prévio dos alunos e respeitando as estruturas cognitivas, objetivando um melhor processo de construção de conhecimentos e dinamismo no ensino dessa área. (TOCANTINS, Referencial Curricular do ensino Fundamental, 2008, p. 59).

Considerando-se que a elaboração do RC/TO mobilizou, entre seus autores, a participação dos professores da rede estadual de ensino (TOCANTINS, 2008, p. 13), criou-se "expectativa de que orientações de 'como trabalhar conteúdos em sala de aula' fossem apresentadas, ampliando o espaço da prática escolar na diretriz local que orienta o ensino de língua materna" (SILVA; MELO, 2009, p. 38). Dito de outra forma esperava-se poder, finalmente, principiar, de forma efetiva, a renovação das práticas escolares.

O Referencial Curricular do Tocantins afirma, em sua parte introdutória, que à escola cabe o papel de cumprir sua atribuição legal e atuar na formação do cidadão:

(...) Exige-se que a escola cumpra com a sua atribuição legal e atue decididamente na formação de um cidadão capaz de entender e interpretar a ciência, as tecnologias, as artes, a diversidade humana e os valores éticos, políticos e estéticos, para assumir de fato seu papel na construção de uma sociedade mais justa e solidária. (TOCANTINS, Referencial Curricular do ensino Fundamental, 2008, p. 13).

É importante reafirmar que o RC/TO teve suas primeiras respirações, mesmo que em tese, em um amplo debate, em um conjunto de esforços despendidos pelos diversos atores do cenário educacional do Tocantins. Nessa perspectiva, o próprio Referencial Curricular se caracteriza como:

(...) uma construção coletiva que mobilizou professores universitários, técnicos da Seduc e educadores da rede estadual de ensino, promovendo um rico momento de discussão e de comprometimento com as proposições assumidas em prol da melhoria da escola pública do Tocantins (TOCANTINS, Referencial Curricular do ensino Fundamental, 2008, p. 13).

Dentre os objetivos de criação desse documento figura a explicitação de uma:

(...) concepção teórica e metodológica sobre o processo educativo que oriente o sistema estadual de ensino, sendo um referencial de apoio na elaboração do Projeto Político Pedagógico de cada unidade escolar [...] possui as marcas das experiências dos professores do Tocantins e reflete os verdadeiros ideais da comunidade educacional e da sociedade tocantinense (TOCANTINS, Referencial Curricular do ensino Fundamental, 2008, p. 13 grifos nossos).

Dessa forma, o referencial finca cercas firmes entre os domínios da proposta e os da execução. Conquanto ostentando a bandeira da construção coletiva, o referencial assume, no interior do seu discurso, um tom prescritivo, também a exemplo dos PCN. Ou seja, o RC/TO traz, em suas proposições, sob o escudo dos estudos linguísticos, um pretenso como fazer. Cabe ao professor, então, o dever fazer, trilhar pelos caminhos que se apontam no documento oficial, executar tais propostas. Inovar sua prática, portanto.

De acordo com o RCLE/TO, o professor ao ministrar os diversos conteúdos referentes à disciplina de LE, não deve se limitar ao estudo conceitual da língua. Portanto, ao 
trabalhar os conteúdos selecionados o docente deverá estar atento ao desenvolvimento das seguintes habilidades:

1- Entender e respeitar as diversidades étnicas, bem como as diferenças e limites individuais e coletivos, interagindo ativamente durante as atividades que exijam a participação de todos respeitando a fala do outro e compreendendo o silêncio como parte de interação. 2- Solucionar eventuais problemas durante as atividades, dentro e fora da sala de aula, através do diálogo, evitando conflitos interpessoais e compreendendo que as atividades de aprendizagem podem ser adaptadas para a inclusão de todos.

3- Utilizar-se de suas habilidades (visuais, auditivas e ou sinestésicas) sendo criativo durante as múltiplas situações que envolvem o processo de ensino e aprendizagem de uma segunda língua.

4- Utilizar-se de materiais lúdicos no processo de ensino e aprendizagem, aprimorando e aperfeiçoando o seu conhecimento linguístico. (TOCANTINS, Referencial Curricular do ensino Fundamental, 2008, p. 222 grifos nossos).

Para a aquisição e o desenvolvimento dessas habilidades supracitadas, o professor deve ser a parte principal nesse processo, pois deverá proporcionar atividades escritas, orais, leituras, dramatizações, além de tarefas interativas e lúdicas. Estas atividades auxiliarão os alunos no aumento da criatividade e no reconhecimento de suas habilidades.

Em relação ao ensino de LE, o Referencial curricular do Tocantins (2008) atesta como um dos objetivos de ensino:

Vivenciar uma experiência de comunicação humana, pelo uso de uma língua estrangeira, no que se refere a novas maneiras de se expressar e ver o mundo, refletindo sobre os costumes ou maneiras de agir e interagir e as visões de sua própria realidade, possibilitando maior entendimento de um mundo plural e de seu próprio papel como cidadão integrante do mesmo. (TOCANTINS, Referencial Curricular do Ensino Fundamental, 2008, p. 219).

O documento defende que a linguagem amplia as possibilidades de participação social do aprendiz no exercício da cidadania. Em todos os níveis de ensino, os gêneros textuais serão a base de desenvolvimento das competências e habilidades a serem trabalhadas, descritas em quadro motriz em cada série, delineando os conteúdos mínimos a serem trabalhados. As orientações didáticas que seguem a esse "guia prático" exige do professor tratamento adequado com o material didático

Quanto à organização textual, o professor deverá explorar o maior número possível de gêneros textuais, levando o aluno a conhecer a estrutura dos diferentes textos, com a finalidade de facilitar a compreensão de textos em Língua Inglesa e a sua utilização em seu cotidiano de forma contextualizada. (TOCANTINS, Referencial Curricular do Ensino Fundamental, 2008, p. 220).

Notou-se, entretanto que a palavra criatividade é contemplada no Referencial Curricular do ensino de Língua Estrangeira, levando-nos a compreender que o termo encontra-se nas observações processadas em torno da prática de produção de textos e principalmente na prática da oralidade. A proposta da orientação didática é de que:

Quanto à oralidade, o professor deverá utilizar-se de fitas ou cds e outros recursos tecnológicospara que o educando possa ouvir um nativo de língua e dessa forma ir aprimorando a sua pronúncia. Assim a criatividade e a curiosidade dos alunos estarão sendo muito estimulados passando a desenvolver uma grande capacidade de concentração. (TOCANTINS, Referencial Curricular do Ensino Fundamental, 2008, p. 248). 
Entendemos que esses saberes referendados e a ampliação da capacidade de expressão abarcariam a criatividade do aluno na construção e desconstrução dos processos cognitivos a que se submete no aprendizado da LE. Todavia, em tempos de estímulo à criatividade, quando os sujeitos professores-alunos são convidados a criar, baseados em suas vivências, valores e identidade seria de extrema relevância a ampliação do conceito criativo no Referencial Curricular.

Quando não há referência ao termo criatividade, os componentes semânticos possibilitados pela leitura e criação participativa na composição dos diferentes gêneros de texto, talvez determinem a figurativização implícita no objeto questão (criatividade), sem a necessidade de sua menção.

Além disso, diferentemente das ciências exatas ou biológicas, em que os resultados são processados e por vezes demonstrados em tempo recorde, nas ciências humanas, especificamente, no estudo da língua e de seus processos, essa avaliação se faz demorada em razão de vários fatores que semanticamente estão acoplados a ela. Contudo, nesse processo a escola deve usar estratégias que desenvolva nos alunos a capacidade de se criar, articular, relacionar os diferentes saberes, conhecimentos, atitudes e valores construídos por intermédio da vivência e dos conhecimentos específicos.

A escolha lexical das citações diretas referenciadas implica na utilização de ações que incluem o outro (mobilizar, apoiar, marcar, refletir), chamam o outro à colaboração. No terceiro e quarto enunciado (citação), o Referencial Curricular assume a posição de sujeito ("construção"; "referencial de apoio").

Contudo, a ênfase em sua construção coletiva ("que mobilizou professores universitários, técnicos da SEDUC e educadores da rede estadual de ensino"), conduz-nos à depreensão de que os objetivos, estratégias e metodologias ali vinculadas são de conhecimento detodos os atores educacionais (pois da elaboração deles fizeram parte), inclusive daqueles responsáveis por efetivá-lo na escola e na sala de aula.

Quando é atestado, na segunda citação, a participação na construção desse Referencial Curricular das "marcas das experiências dos professores do Tocantins" e "os verdadeiros ideais da comunidade educacional e da sociedade tocantinense", aqui, além de o discurso sinalizar para a participação de agentes educacionais envolvidos na construção do documento, inclui nesse processo a contribuição de "verdadeiros" ideais da comunidade e da sociedade. A dicotomia entre verdadeiro $\mathrm{x}$ falso aqui se instala, legitimando o primeiro (verdadeiro) como aquele usado na construção do documento, logo, o que é alheio a esse verdadeiro foi descartado.

Verdadeiro sob o ponto de vista de quem, se o RC/TO tem suas bases firmadas sobre os PCN? A ênfasena participação coletiva, nesse caso, pode figurar como "condensação que recobre estruturas narrativas e discursivas bastante complexas", conduzindo-nos "à depreensão éthos do enunciador (SEDUC/TO), que está tomado pelo sentimento que imprime ao produto de seu ato enunciativo" (GREIMAS, 1983, apud FIORIN, 2007, p. 12).

\section{Considerações finais}

Parece-nos que a elaboração do RC/TO ora analisado, especificamente do ensino de Língua Estrangeira, traz-nos a sensação de que diferentes sistemas instrucionais são representados por intermédio de fluxogramas vazios. Não vazios, de fato, mas que retratam as atividades a serem processadas como aspecto distintivo e imperativo para o ensino da LE e pouco sinalizam acerca de como criá-las e em que contexto utilizá-las. 
Começar processos de mudanças implica, inevitavelmente, ação criativa. E criar implica desconstrução. Nesse sentido, Pedro Demo (2010) afirma que o dilema do professor é inovar-se a si mesmo para poder, então, inovar a sua prática. Acreditamos ser isso a maior dificuldade que se ergue contra o professor na busca por seu objetivo, a mudança de sua prática pedagógica. Não significa dizer, em palavra alguma, que os professores sejam resistentes a novas formas de gerir a sua prática. Ao contrário, aceitam o acordo que o documento oficial oferece, inquietam-se em cumpri-lo; sabem o que querem. Falta-lhes criatividade, entretanto.

Constatou-se que o RCLE/TO analisado indica a necessidade de uma linguagem dialógica, ele traz orientações a serem seguidas, é uma espécie de subsídio para a organização mental que permitirá ao professor efetivar os conteúdos a serem trabalhados no espaço escolar. Em seus norteamentos, o referido documento chama a atenção para a importância de o material didático atender a diferentes interesses e perfis cognitivos dos alunos, induzindonos a crer que estarmos diante de um cenário facilmente traduzido em ações e bons resultados. A repetição nele apontada, como um mantra, sobre a necessidade de estímulo à autonomia do aluno não desfaz o que normalmente ocorre nesse processo: a confusão de que autonomia sinaliza para uma tremenda carga de atividades e exercícios associados a muitas contradições.

Privilegia-se na composição do RC/TO analisado mais a natureza descritiva das teorias da aprendizagem que a natureza prescritiva, aquela que, por exemplo, busca explicações do como e por que aplicar tais diretrizes no ensino de (LE), em detrimento de elementos e estratégias de ensino que descrevem o estudo de gêneros de texto, numa espécie de um estudo meramente de significados.

Diante disso, finalizamos essa pequena análise sinalizando para o que propaga os PCN quanto à necessidade de um ensino contextualizado, versátil e que envolva a interdisciplinaridade e a criatividade do aluno:

Se a aprendizagem for uma experiência de sucesso, o aluno constrói uma representação de si mesmo como alguém capaz. Se, ao contrário, for uma experiência de fracasso, o ato de aprender tenderá a se transforma em ameaça, e a ousadia necessária se transformará em medo, para o qual a defesa possível é a manifestação do desinteresse (PCN, 2000, p. 53).

Aos atores educacionais, impõe-se o desafio de validar esse conhecimento envolvendo tanto os níveis de organização do pensamento quanto os conhecimentos e experiências prévias do aluno, vinculados aos processos de interação, não como um simples trânsito visando à meta seguinte, como um porto de passagem rumo à meta, mas como abertura ao descobrimento das coisas, tendo o pensamento, a fantasia, as vivências e a criatividade como aliados.

No entanto, ações isoladas de um ou outro professor em pouco ou em nada contribuem para o início de mudanças efetivas. $\mathrm{O}$ ato interdisciplinar, criativo e a ação inovadora passam por caminhos diversos, mas acreditamos na criatividade como potencial humano e na inovação como projeção social. Nesse sentido, as mudanças que os novos tempos reclamam só serão possíveis se forem resultado do esforço coletivo de atores diversos, em especial, formadores, professores e instâncias públicas competentes na elaboração/execução de projetos que possam, de fato, nortear os novos rumos da educação. Sem uma noção de responsabilidade mútua e interdisciplinar, cada um continuará, a seu modo, acomodado ao faz de conta pedagógico. 


\section{Referências}

ALMEIDA FILHO, J. C. P. Dimensões comunicativas no ensino de línguas. $3^{\mathrm{a}}$ ed. Campinas: Pontes Editores, 2002.

ANTUNES, C. A criatividade na sala de aula. Fascículo 14. $5^{\mathrm{a}}$ ed. Vozes. Petrópolis, RJ, 2009.

BARRETO, C. C. Desenho instrucional em materiais didáticos impressos - uma boa idéia. Disponível

http://pigead.lanteuff.org/pluginfile.php/26911/mod_resource/content/3/DesignDid\%C3\%A1t ico.pdf. Acesso em 03 de Agosto de 2013.

BAKHTIN, M. Estética da criação verbal. São Paulo: Martins Fontes, 2003.

BRASIL. Secretaria de Educação Fundamental. Parâmetros curriculares nacionais: língua portuguesa /Secretaria de Educação Fundamental. Brasília, 1997, 144p.

- Minério da Educação. Secretaria de Educação Fundamental. Parâmetros Curriculares Nacionais: terceiro e quarto ciclos do ensino fundamental: Língua Estrangeira. Brasília: MEC/SEF, 1998.

- Parâmetros Curriculares Nacionais. Introdução aos Parâmetros Curriculares Nacionais. $2^{\mathrm{a}}$ ed. Rio de Janeiro: DP\&A, 2000. 126p.

- Ministério da Educação. Secretaria de Educação Média e Tecnológica. Parâmetros Curriculares Nacionais: Ensino Médio. Brasília, DF: Ministério da Educação, 2002.

.Ministério da Educação. Secretaria de Educação Básica. Orientações Curriculares Nacionais para o Ensino Médio. Linguagens, Códigos e suas Tecnologias. Brasília: Ministério da Educação, Secretaria de Educação Básica, 2006.

COSTA, M. E. M.; MARINS, V. Design Didático em Ambientes Virtuais. UFF, s.d, não paginado. Disponível

em http://pigead.lanteuff.org/pluginfile.php/26911/mod_resource/content/3/DesignDid\%C3\%A1t ico.pdf. Acesso em: 13 de agosto de 2013.

DEMO, P. Rupturas urgentes em educação. Ensaio: aval. pol.públ. Educ. Rio de Janeiro, v. 18, n. 69, p. 861-872, out./dez. 2010.

FAZENDA, I. C. A. Práticas interdisciplinares na escola. $8^{\mathrm{a}}$ ed. São Paulo: Corte editora, 2001. . (Org.) Didática e interdisciplinaridade. 9ª ed. Campinas, SP: Papirus, 2005. . Interdisciplinaridade: história, teoria e pesquisa. $18^{a}$ ed. São Paulo: Papirus, 2010.

FIORIN, J. L. Semiótica das paixões: o ressentimento. São Paulo: Alfa, v. 51, n.1, 2007. 
LÜCK, H. Pedagogia interdisciplinar: fundamentos teórico-metodológicos. Rio de Janeiro: Vozes, 2010.

MARCONI, M. A.; LAKATOS, E. M. Metodologia Científica. 5. ed. São Paulo: Atlas, 2008.

MORAES, M. C. O paradigma Educacional Emergente. Campinas, SP: Papirus, 2003.

SILVA, W. R.; MELO, L. C. de. Teoria acadêmica e prática docente em referencial curricular. In: SILVA, W. R.; MELO, L. C. de (Orgs.). Pesquisa \& ensino de língua materna e literatura: diálogos entre formador e professor. Campinas: Mercado de Letras; Araguaína: Universidade Federal do Tocantins-UFT, 2009. p. 37-62.

TOCANTINS. Secretaria de Estado da Educação e Cultura. Referencial Curricular do Ensino Fundamental das escolas públicas do Estado do Tocantins: Ensino Fundamental do $1^{\circ}$ ao $9^{\circ}$ ano. $2^{a}$ Edição. Secretaria de Estado da Educação e Cultura. Palmas/TO: 2008. 281 p.

TORRE, S. de La. La Adversidad esconde um tesoro: Outra manera de ver laadversidad y la vida. Barcelona: Editorial Círculo Rojo - Investigación, 2011.

. Instituciones educativas creativas. Barcelona: Editorial Círculo Rojo, 2012.

WERTSCH, J. V. Voces de la mente, un enfoque sociocultural para El estudio de laacción mediada (trad. Adriana Silvestri) Madrid: Visor, 1993.

Recebido em: julho de 2014.

Aprovado em: dezembro de 2014. 